\title{
Gender differences in first episode psychotic mania
}

\author{
Sue M Cotton ${ }^{1,2^{*}}$, Martin Lambert ${ }^{3}$, Michael Berk ${ }^{1,2,4,5}$, Benno G Schimmelmann ${ }^{6}$, Felicity J Butselaar ${ }^{1,2}$, \\ Patrick D McGorry ${ }^{1,2}$ and Philippe Conus $^{7}$
}

\begin{abstract}
Background: The aim of this paper was to delineate the impact of gender on premorbid history, onset, and 18 month outcomes of first episode psychotic mania (FEPM) patients.

Methods: Medical file audit assessment of 118 (male $=71$; female $=47$ ) patients with FEPM aged 15 to 29 years was undertaken on clinical and functional measures.

Results: Males with FEPM had increased likelihood of substance use $(O R=13.41, p<.001)$ and forensic issues $(O R=4.71, p=.008)$, whereas females were more likely to have history of sexual abuse trauma $(O R=7.12, p=.001)$. At service entry, males were more likely to be using substances, especially cannabis ( $O R=2.15, p=.047)$, had more severe illness $(O R=1.72, p=.037)$, and poorer functioning $(O R=0.96, p=.045)$. During treatment males were more likely to decrease substance use $(O R=5.34, p=.008)$ and were more likely to be living with family $(O R=4.30, p=.009)$. There were no gender differences in age of onset, psychopathology or functioning at discharge.

Conclusions: Clinically meaningful gender differences in FEPM were driven by risk factors possibly associated with poor outcome. For males, substance use might be associated with poorer clinical presentation and functioning. In females with FEPM, the impact of sexual trauma on illness course warrants further consideration.
\end{abstract}

Keywords: Gender, Mania, Psychosis, Bipolar disorder

\section{Background}

Gender differences in incidence, pre-illness characteristics, onset and course have been widely documented in psychotic disorders such as schizophrenia [1-4]. Less is known regarding gender differences in bipolar I disorder. There are epidemiological studies indicating substantive gender differences in the incidence, presentation and course of bipolar I disorder; however, the extent of these differences is yet to be fully delineated. An equal gender ratio has been reported for bipolar I disorders [5]; however, other studies indicate that males may be more likely to be at risk of bipolar I disorder [6], or conversely that there is a higher incidence of bipolar I disorder in females [7].

There have been inconsistencies regarding age of illness onset for bipolar I disorder with some studies reporting absence of gender differences in age of onset [8], while others have documented an earlier onset in females [9] or

\footnotetext{
* Correspondence: smcotton@unimelb.edu.au

'Orygen Youth Health Research Centre, University of Melbourne, Locked Bag

10 (35 Poplar Road), Parkville, Victoria 3052, Australia

${ }^{2}$ Centre for Youth Mental Health, The University of Melbourne, Parkville,

Victoria, Australia

Full list of author information is available at the end of the article
}

an earlier onset in males $[7,10]$. The age range of patients included in cohorts is an important issue. Gender differences in age of onset of bipolar disorder may vary depending on the decade under investigation. Between 16-25 years of age, bipolar disorder may be more common in males, whereas across the other decades, females with bipolar disorder may predominate $[7,11]$. Developmental variations across the lifespan including cortical maturation, psychosocial development, and changes in the female reproductive cycle [10], need to be considered in the context of such findings.

Reported gender differences in course of illness have also been varied. In terms of symptomatology, females may have more severe depressive symptoms $[9,10,12]$, more mixed symptoms [13], psychotic symptoms including paranoid delusions and delusions of reference [12], and be more likely to experience rapid cycling [9]. Other studies have found no such differences $[8,14]$. Polarity of the incipient mood episode may also contribute to variation in gender differences. Males with bipolar I disorder may be more likely to have mania as their first episode whereas females are more likely to have a depressive episode [8].

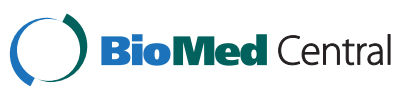

(c) 2013 Cotton et al.; licensee BioMed Central Ltd. This is an Open Access article distributed under the terms of the Creative Commons Attribution License (http://creativecommons.org/licenses/by/2.0), which permits unrestricted use, distribution, and reproduction in any medium, provided the original work is properly cited. 
Less is known about gender differences in social and occupational functioning, with more emphasis being placed on symptomatology. However, Miquel et al. [15] reported that a higher proportion of females than males with acute mania, either lived independently or resided with a partner. No gender differences were observed in participation in work or social activities.

Unrepresentative and small samples may contribute to the variability in findings on gender differences in bipolar disorder. Often chronic patients or inpatients have been recruited; such cohorts have experienced a broad range of primary stressors prior to illness as well as secondary stressors associated with the illness (e.g., acute illness phases, relapses and medication).

To date, research on the gender differences in patients with first episode mania (FEM) is sparse. There appears to be only one study that has involved the investigation of gender differences in a FEM cohort. Kennedy et al., [7] focused on incidence across a wide age range (16 to 76 years+) and identified all adult cases with bipolar I disorder and FEM who had been in contact with services in a defined catchment area in south east London. They also considered a range of psychosocial factors that may relate to gender differences in age of onset. Males with FEM had an earlier onset disorder than females, and were also more likely to have a history of antisocial behaviour in childhood [7].

None of the studies conducted to date have examined gender differences in the subgroup of patients who have first episode psychotic mania (FEPM). Indeed, approximately $50 \%$ of patients will have psychotic symptoms at some stage of their illness [16]. Further, as around 70\% of clients with bipolar disorder have incipient symptoms before the age of 25 years [17], it is important to consider whether there are gender differences in young adults with FEPM in terms of premorbid histories, entry characteristics, treatment, and discharge characteristics.

Therefore, in the current study, we report on gender differences in illness course of an epidemiologically representative treated cohort of patients with FEPM, aged between 15-29 years of age. It was hypothesized that there would be gender differences in clinical and functional characteristics of patients presenting with FEPM.

\section{Method}

\section{Sample and setting}

One hundred and eighteen patients with a discharge diagnosis of FEPM were selected from a larger cohort of patients with first episode psychosis (FEP) from the First Episode Psychosis Outcome Study (FEPOS). FEPOS comprised a file audit of all 786 FEP patients treated at the Early Psychosis Prevention and Intervention Centre (EPPIC) between January 1998 and December 2000 [1,18-27]. EPPIC provides a comprehensive specialist program for young people aged 15-29 years experiencing their first episode of psychosis. Its catchment area covers the north-western regions of Melbourne, Australia [28]. At the time of the study, EPPIC treated most patients with psychosis, with very little leakage into the private system [20]. On the basis of these characteristics, FEPOS has been considered to comprise a treated epidemiological cohort [20].

Institutional ethics approval was obtained from Mental Health Research and Ethics Committee, Melbourne Health, Victoria, Australia. As this was a medical file audit study, informed consent was not required to be obtained from patients.

\section{Materials and procedure}

The Early Psychosis File Questionnaire [20] was used to systematically assess consecutive medical files.

Clinical diagnoses at EPPIC are derived through consensus during an intensive diagnostic and treatment process. An initial diagnosis is determined during the first 6 weeks of admission by the team of well-trained clinicians, and is reviewed over the course of treatment. FEPOS diagnoses were given according to DSM-IV and on the basis of all information detailed in the medical file [20]. Given the issues with diagnostic instability in early illness course, we used final discharge diagnosis to identify the cohort of FEPM patients used in the current study [23].

Pre-morbid characteristics recorded included: past history of DSM-IV psychiatric disorder; past history of DSMIV substance use disorder; suicide attempts (classified on ICD-10 criteria); family history of psychiatric disorder; premorbid adjustment as assessed by the Global Assessment of Functioning (GAF); age at onset of psychotic symptoms; and duration of untreated psychosis (age of entry into EPPIC subtracted by age when first sustained positive psychotic symptoms longer than a week duration).

At service entry, clinical diagnoses (including substance use) were ascertained according to DSM-IV criteria. Illness severity was assessed according to scores on the Clinical Global Impressions-Severity of Illness Scale [29] and the Clinical Global Impressions-Bipolar Illness (CGI-BP). Insight was coded on a three point scale ( 0 'absence of insight; 1 'partial insight-perception of being ill but persistence of illogical explanations'; and 2 'full insight').

Global functioning was assessed using the GAF. Vocational functioning was determined using the Modified Vocational Status Index (MVSI) and the Modified Location Code Index (MLCI) was used to determine independent living status [30].

Treatment information included: suicide attempts; inpatient admissions; medication non-compliance ( $\geq 1$ week without taking medication); and service engagement.

At service discharge, the final file DSM-IV clinical diagnoses were recorded. Symptom severity was determined 
using CGI-S, CGI-BP, and the insight scale. The GAF, MVSI, and MLCI, were used to assess discharge functional status. Patterns of substance use over treatment was also documented and characterised by three categories: (i) no SUD; (ii) decreased or remitted (decrease in quality and frequency of $\geq 50 \%$ or remission of baseline at 18 months or time of discharge); and (iii) persistent SUD (either increased SUD or unchanged SUD) [20].

\section{Reliability and validity}

Estimates obtained for inter-rater reliability for the CGI, CGI-BP, GAF, and insight for 40 files were good (range: $\kappa=0.87$ for CGI-S to $\kappa=0.89$ for insight score) [20]. The SCID-I/P was used to determine the validity of diagnoses for a subset of 115 patients (see Conus et al., 2007). There was good concordance for both psychotic $(\kappa=0.80)$ and substance use $(\kappa=0.74)$ diagnoses.

\section{Data analysis}

A series of logistic regression analyses were conducted with gender as the dependent variable (male as the reference category), and the individual premorbid and service entry variables as predictors. From these analyses, odds ratios $(O R)$ and the $95 \%$ confidence intervals $(\mathrm{CI})$ of the ORs were derived. The Wald statistic (z) was used to determine significance of predictors. For the treatment and discharge variables, adjusted ORs and $95 \% \mathrm{CI}$ of the adjusted ORs were reported, controlling for entry characteristics and time in service.

Multivariate logistic regression with forward stepwise variable selection (based on the likelihood ratio) was used to determine which factors best differentiated males and females with FEPM. Variables included in the equation were those that were different by gender in the univariate analyses at the $p<.100$ level.

Given the exploratory nature of the study, alpha $(\alpha)$ was set at .05 for all analyses. No adjustments were made for multiple comparisons because they can result in a higher type II rate, reduced power, and increased likelihood of missing important findings (Rothman, 1990).

\section{Results}

The majority of patients were male $(60.2 \%, n=71)$. Given the ratio of males to females, we had around $75 \%$ power to detect moderate effects (differences between the two genders). Previous studies of gender differences in psychotic disorders have reported moderate to large effects [1]; thus we had an adequate sample size to power the study.

The average age of onset of illness was 22.2 years $(S D=$ 3.2 , $\min =15, \max =29)$ and the average age at entry to the service was 22.4 years $(S D=3.2$, $\min =15, \max =30)$.

Males with FEPM were more likely to have a past history of substance use $(O R=4.86, p<.001)$ and forensic issues $(O R=14.79, p=.008)$. Females with FEPM were more likely to have experienced sexual abuse trauma $(O R=7.12, p=.001)^{\text {a }}$ (see Table 1$)$.

At service entry, males were significantly more likely to have substance use issues $(O R=3.98, p=.001)$; with cannabis use prominent $(O R=4.58, p=.047)$. Males also had more severe illness (CGI-S, $O R=1.72, p=.037$ ) and poorer functioning (GAF, $O R=0.96, p=.045)$ compared to females with FEPM (see Table 1). During treatment males with FEPM were more likely to decrease or stop their substance use $(O R=5.34, p=.008)$ than females with FEPM. At discharge males were more likely to be living with their families $(O R=4.30, p=.009)$, but there were no gender differences in discharge psychopathology or functioning (see Table 2).

A range of variables in the univariate analyses distinguished males and females at the $p<.100$ level including: past history of substance use; exposure to sexual abuse; forensic issues; substance use at service entry; CGI-S at entry; GAF at entry; admissions to hospital; substance use at discharge; and whether or not living with a family at discharge. These variables were entered into a multivariate logistic regression model to determine which factors best delineated differences between males and females. Past history of substance use $(O R=$ 20.33, 95\% CI OR 6.13-67.42, $p<.001)$, exposure to sexual abuse $(O R=0.11,95 \%$ CI $O R 0.02-0.53, p=.006)$, and living with family at discharge $(O R=3.33,95 \% \mathrm{CI}$ OR 1.06-10.41, $p=.039)$ were the variables that best discriminated between males and females with FEPM.

\section{Discussion}

To our knowledge, this the first study to comprehensively examine gender differences in illness onset and course in a treated epidemiological cohort of patients with FEPM. A further strength of the study is that we included all patients who first presented for treatment and not just those patients with more severe or chronic illness or those who have had their first inpatient admission. Similar to previous studies into patients with chronic illness and bipolar I disorder, we found an array of gender differences in patients with FEPM between the ages of 15 to 29 years. Key differences were found with respect to premorbid history, severity of illness at entry, treatment and discharge characteristics.

Univariate analyses indicated that males with FEPM were more likely to have a history of substance and forensic issues. It has previously been shown that males with bipolar disorder are more likely to have conduct problems or antisocial tendencies in childhood $[7,8]$ which may increase the likelihood of violence [31] and problems with the law $[14,32]$. Substance use (especially, alcohol, cannabis and nicotine) also tends to be more common in males than females with bipolar disorder 
Table 1 Demographic, diagnostic, premorbid, pre-treatment and service entry factors related to gender in FEPM patients

\begin{tabular}{|c|c|c|c|c|c|c|c|}
\hline \multirow[b]{2}{*}{ Variable } & & \multicolumn{2}{|c|}{ Gender } & \multirow[b]{2}{*}{ OR } & \multicolumn{2}{|c|}{$95 \% \mathrm{Cl}$ of OR } & \multirow[t]{2}{*}{$\mathrm{p}$ value } \\
\hline & & $\begin{array}{c}\text { Male } \\
(n=71)\end{array}$ & $\begin{array}{l}\text { Female } \\
(n=47)\end{array}$ & & $\mathrm{LCl}$ & $\mathrm{UCl}$ & \\
\hline \multicolumn{8}{|l|}{ Pre-treatment variables } \\
\hline Years in school & M (SD) & $11.2(1.3)$ & $11.0(1.6)$ & 1.12 & 0.86 & 1.45 & .395 \\
\hline Pre-morbid GAF & $\mathrm{M}(\mathrm{SD})$ & $73.9(11.5)$ & $74.8(9.4)$ & 0.99 & 0.96 & 1.03 & .638 \\
\hline Duration of prodrome (in days) ${ }^{a}$ & $\mathrm{M}(\mathrm{SD})$ & $363.0(640.0)$ & $227.2(338.0)$ & 1.15 & 0.83 & 1.60 & .398 \\
\hline Duration of untreated psychosis (in days) ${ }^{a}$ & M (SD) & $41.4(197.2)$ & $64.93(190.9)$ & 0.76 & 0.50 & 1.16 & .204 \\
\hline Age at onset (years) & $\mathrm{M}(\mathrm{SD})$ & $22.0(3.0)$ & $22.5(3.6)$ & 0.95 & 0.85 & 1.07 & .387 \\
\hline Past history of suicide attempt (\%Yes) & $\%(n)$ & $2.8(2)$ & $8.7(4)$ & 0.30 & 0.05 & 1.73 & .180 \\
\hline Family history of psychiatric disorder & $\%(n)$ & $60.9(42)$ & $72.1(31)$ & 0.60 & 0.26 & 1.37 & .227 \\
\hline \multicolumn{8}{|l|}{ Diagnostic variables } \\
\hline \multicolumn{8}{|l|}{ Past history } \\
\hline Major depressive disorder & $\%(n)$ & $49.3(35)$ & $63.8(30)$ & 0.55 & 0.26 & 1.17 & .122 \\
\hline Substance use disorder (SUD) (\%Yes) & $\%(n)$ & $91.5(65)$ & $44.7(21)$ & 13.41 & 4.86 & 37.01 & $<.001$ \\
\hline Sexual abuse & $\%(n)$ & $5.6(4)$ & $29.8(14)$ & 0.14 & 0.04 & 0.46 & .001 \\
\hline Physical abuse & $\%(n)$ & $14.1(10)$ & $19.1(9)$ & 0.69 & 0.26 & 1.86 & .465 \\
\hline Forensic issues & $\%(n)$ & $30.4(21)$ & $8.5(4)$ & 4.71 & 1.50 & 14.79 & .008 \\
\hline \multicolumn{8}{|l|}{ At service entry } \\
\hline Comorbid psychiatric disorder (\%Yes) & $\%(n)$ & $4.2(3)$ & $4.3(2)$ & 1.01 & 0.16 & 6.27 & .994 \\
\hline Substance use disorder (SUD) (\%Yes) & $\%(n)$ & $74.6(53)$ & $42.6(20)$ & 3.98 & 1.81 & 8.74 & .001 \\
\hline Cannabis & $\%(n)$ & $54.9(39)$ & $36.2(17)$ & 2.15 & 1.01 & 4.58 & .047 \\
\hline Alcohol & $\%(n)$ & $11.3(8)$ & $12.8(6)$ & 0.87 & 0.28 & 2.68 & .805 \\
\hline Polysubstance & $\%(n)$ & $14.1(10)$ & $8.5(4)$ & 1.76 & 0.52 & 5.99 & .364 \\
\hline \multicolumn{8}{|l|}{ Baseline variables } \\
\hline Age at service entry & $\mathrm{M}(\mathrm{SD})$ & $22.3(3.0)$ & $22.7(3.4)$ & 0.96 & 0.85 & 1.08 & .469 \\
\hline \multicolumn{8}{|l|}{ Symptoms at entry } \\
\hline CGI-S severity score & M (SD) & $5.8(0.8)$ & $5.5(0.7)$ & 1.72 & 1.03 & 2.86 & .037 \\
\hline CGI-BP depression & $\mathrm{M}(\mathrm{SD})$ & $1.5(1.3)$ & $1.4(1.3)$ & 1.11 & 0.81 & 1.51 & .520 \\
\hline CGI-BP mania & $\mathrm{M}(\mathrm{SD})$ & $4.7(1.8)$ & $4.6(1.5)$ & 1.05 & 0.84 & 1.31 & .657 \\
\hline Insight at entry (\%No) & $\%(n)$ & $76.1(54)$ & $65.2(30)$ & 1.69 & 0.75 & 3.83 & .205 \\
\hline \multicolumn{8}{|l|}{ Functional level at entry } \\
\hline Employment/occupation (\%Yes) & $\%(n)$ & $63.4(45)$ & $72.3(34)$ & 0.66 & 0.30 & 1.47 & .312 \\
\hline GAF & M (SD) & $29.7(10.1)$ & $33.5(9.1)$ & 0.96 & 0.92 & 0.99 & .045 \\
\hline Living with family & $\%(n)$ & $54.3(38)$ & $44.7(21)$ & 1.47 & 0.70 & 3.09 & .309 \\
\hline
\end{tabular}

Note: OR - odds ratio; LCI - lower confidence interval; UCI - upper confidence interval; CGI-S - Clinical Global Impressions Scale - Severity; CGI-BP - Clinical Global Impressions Scale - Bipolar Disorder; GAF - Global Assessment of Functioning.

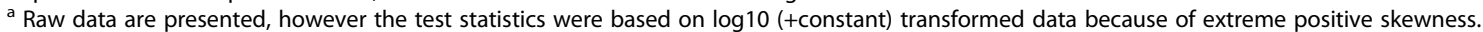

$[9,10,15,33]$, and might explain the increased prevalence of forensic issues [34] in our cohort.

Gender differences in the prevalence of substance use disorders have been reported in the general population, with males being more likely to abuse or be dependent on drugs [35]. At service entry, $74.6 \%$ of males and $42.6 \%$ of females were using substances; much higher than rates in the general population. The persistent substance use in males, particularly prior to, and at the onset of the psychotic mania, might in part explain their more severe levels of psychopathology and poorer functioning (as measured by the GAF). This is supported by findings that substance use in patients with bipolar disorder is associated with poorer social adjustment and outcome [36].

Males were more likely to use cannabis than females with FEPM; but no such gender differences were found with alcohol or polysubstance use. Cannabis use is 
Table 2 Treatment and discharge characteristics of males and females with FEPM

\begin{tabular}{|c|c|c|c|c|c|c|c|}
\hline \multirow[b]{2}{*}{ Variable } & & \multicolumn{2}{|c|}{ Gender } & \multirow[b]{2}{*}{ OR } & \multicolumn{2}{|c|}{$95 \% \mathrm{Cl}$ of $\mathrm{OR}$} & \multirow[t]{2}{*}{$\mathrm{p}$ value } \\
\hline & & $\begin{array}{c}\text { Male } \\
(n=71)\end{array}$ & $\begin{array}{c}\text { Female } \\
(n=47)\end{array}$ & & $\mathrm{LCl}$ & $\mathrm{UCl}$ & \\
\hline \multicolumn{8}{|l|}{ Treatment variables } \\
\hline Length of time in service (in weeks) & $M(S D)$ & $64.8(34.1)$ & $59.1(30.1)$ & 1.01 & 0.99 & 1.02 & .353 \\
\hline Admitted to hospital (\%Yes) ${ }^{a}$ & $\%(n)$ & $91.5(65)$ & 80.9 (38) & 2.71 & 0.89 & 8.30 & .080 \\
\hline Number of admissions ${ }^{a}$ & $M(S D)$ & $1.5(1.1)$ & $1.2(0.8)$ & 1.36 & 0.88 & 2.10 & .173 \\
\hline Compliance with treatment (\%Yes) ${ }^{a}$ & $\%(n)$ & $56.5(39)$ & $50.0(21)$ & 1.28 & 0.59 & 2.77 & .533 \\
\hline \multicolumn{8}{|l|}{ Substance use disorder (SUD) a b } \\
\hline No SUD & $\%(n)$ & $23.9(17)$ & $55.3(26)$ & na & & & \\
\hline Remitted SUD (decreased or stopped) & $\%(n)$ & $56.3(40)$ & $25.5(12)$ & 5.34 & 2.17 & 13.14 & $<.001$ \\
\hline Persistent SUD (increased or no change) & $\%(n)$ & $19.7(14)$ & $19.1(9)$ & 2.93 & 0.97 & 8.89 & .056 \\
\hline Suicide attempt in treatment (\%Yes) ${ }^{a}$ & $\%(n)$ & $7.0(5)$ & $4.3(2)$ & 1.51 & 0.27 & 8.32 & .639 \\
\hline \multicolumn{8}{|l|}{ Symptoms at discharge } \\
\hline CGI-S severity score ${ }^{c}$ & $M(S D)$ & $2.2(1.2)$ & $2.2(1.2)$ & 0.99 & 0.69 & 1.42 & .950 \\
\hline CGI-BP depression ${ }^{d}$ & $M(S D)$ & $1.4(0.9)$ & $1.4(1.0)$ & 0.99 & 0.65 & 1.49 & .953 \\
\hline CGI-BP mania ${ }^{e}$ & $M(S D)$ & $1.4(1.0)$ & $1.5(1.0)$ & 1.03 & 0.65 & 1.64 & .890 \\
\hline Insight at discharge $(\% \mathrm{No})^{\mathrm{f}}$ & $\%(n)$ & $7.0(5)$ & $4.3(2)$ & 1.88 & 0.32 & 11.14 & .485 \\
\hline \multicolumn{8}{|l|}{ Functional level at discharge } \\
\hline Employment/occupation (\%Yes) ${ }^{g}$ & $\%(n)$ & $56.5(35)$ & $72.5(29)$ & 0.50 & 0.19 & 1.31 & .158 \\
\hline $\mathrm{GAF}^{\mathrm{h}}$ & $M(S D)$ & $68.8(14.6)$ & $71.1(12.3)$ & 0.99 & 0.96 & 1.02 & .446 \\
\hline Living with family (\%Yes) ' & $M(S D)$ & $77.0(47)$ & $51.3(20)$ & 4.30 & 1.44 & 12.79 & .009 \\
\hline \multicolumn{8}{|c|}{$\begin{array}{l}\text { Note: OR - odds ratio; } \mathrm{LCl} \text { - lower confidence interval; UCI - upper c } \\
\text { Impressions Scale - Bipolar Disorder; GAF - Global Assessment of Fu } \\
\text { a Covariate was time in service. } \\
\text { b No substance use was reference category in logistic regression. } \\
\text { c Covariates were time in service and CGI-S at entry, unadjusted me } \\
\text { d Covariates were time in service and CGI-BP depression at entry, u } \\
\text { e Covariates were time in service and CGI-BP mania at entry, unadju } \\
{ }^{f} \text { Covariates were time in service and insight at service entry. } \\
\text { g Covariates were time in service and employment status at entry. } \\
\text { h Covariates were time in service and GAF score at entry. } \\
\text { ' Covariates were time in service and living with family at service en }\end{array}$} \\
\hline
\end{tabular}

common in patients with bipolar disorder, particularly in younger patients $(<30$ years) [37,38]. Cannabis use may be associated with an earlier age of onset of bipolar disorder, particularly in vulnerable individuals [38]. However, no such gender differences in age of onset were found in the current study cohort.

During treatment, males were more likely than females to decrease or cease their substance use. Increased familial support in males might have contributed to the reduction of substance use. Males who are ill with a first episode of psychosis are more likely than females to receive understanding and support from family members [39]. This may relate to cultural and societal differences in that underperformance and behavioural issues are tolerated more in males than females [39]. Further, females with psychotic disorders such as schizophrenia are more likely to have experienced childhood adversities [40], and are hence likely to leave home at an early age.
Family involvement in early treatment can be pertinent for minimising the chances of substance use becoming a more serious disorder [41-43]. An alternative explanation might be that the percentage of males who live with their families increases when they stop using substances. The decrease in substance use in males may also account for why there are no differences between the genders in terms of severity of illness and functioning at discharge.

Females were seven times more likely to have experienced sexual abuse than males with FEPM. A recent meta analysis indicated that the prevalence of sexual abuse is higher in females (19.7\%) than males (7.9\%) in the general population [44]. However, in our sample approximately $30 \%$ of females with FEPM had been exposed to sexual abuse; a rate of trauma that is of concern. A relationship between sexual abuse or traumatic experiences and the onset of psychotic disorders 
has been proposed [45-48], and this association may be stronger in females than males [49]. Exposure to such trauma, may negatively affect brain development, through chronic hyper-reactivity of the hypothalamicpituitary-adrenal (HPA) axis. This hyper-reactivity may then lead to disruption in the functions of dopaminergic and serotonergic systems, and may worsen prognosis. Such events sequelae have been described in the "traumagenic neurodevelopmental" model. Although the ultimate alterations to functions in dopaminergic and serotonergic may precipitate the onset of FEPM, there may be broader long-term effects. In females with chronic bipolar disorder, a history of sexual and physical abuse/trauma may relate to poorer mood outcomes such as more shifts in polarity and mixed episodes [50]. Exposure to sexual abuse might also place females with bipolar disorder at a disproportionately greater risk of comorbid anxiety disorders such as post-traumatic stress disorder (PTSD) $[14,47,48,51]$. Because our cohort was young, the possibility of the development of such (generally) longer-term sequelae might not have been captured in this group.

A history of sexual abuse may also explain why females with FEPM were less likely to be living with their families at discharge from the service. If the abuse occurred within the context of the family networks, then this is a unsurprising finding. However, it should also be noted, a history of sexual abuse and/or trauma is linked with markedly poorer social functioning especially with respect to building constructive and trusting relationships [52].

With regards to the characteristics of the current study, a number of factors need to be kept in mind in interpreting the data. FEPM cohorts may offer a unique window into the disorder, as the effects of illness progression and treatment are controlled for. The primary limitation of this study is the use of a retrospective medical file audit. There can be numerous problems with such an approach including: (i) poor quality of documented information; (ii) clinical experience of raters; (iii) lack of inter-rater reliability; and (iv) questionable data validity. Numerous strategies were adopted in the current study to minimise the impact of such limitations including: (i) medical files at EPPIC were systematised according to FEP guidelines [53]; (ii) medical files were rated by two consultant psychiatrists with expertise knowledge of EPPIC and the treatment of FEP; (iii) sound inter-rater reliability was determined for clinical and functioning measures; and (iv) concurrent validity of psychoses and baseline SUD was established for a subsample of patients [20]. The study population was a catchment area sample, and is likely to be broadly representative of the population of FEPM (16).

A further study limitation was the lack of information recorded regarding psychopathology (e.g., mood episodes, psychotic symptoms, relapse) and type and dosage of pharmacological treatments; these factors could have had an effect on the degree of gender difference at discharge.

\section{Conclusions}

It appears that there are substantial differences between males and females with FEPM in terms of past histories, presentation, and discharge outcomes; however, these differences may be driven by putative risk factors such as substance use and exposure to sexual abuse. Importantly, these risk factors occur prior to the onset of full threshold disorder. These risk factors might be markers of a disease that has already been under development for some time. However, given current evidence, it is difficult to ascertain whether substance abuse and/or sexual abuse are a cause or consequence (e.g., prodromal phase of illness) of illness.

There is growing interest in identifying individuals at "ultra high risk" of developing bipolar disorder [54] and who have a clearly defined prodrome $[55,56]$. It has been argued that symptoms alone are unlikely to be sufficient for the correct identification of those at risk of developing bipolar disorder; however, identifying risk factors or markers of vulnerability may improve the accuracy of this prediction [55]. The substance use and sexual abuse findings from the current study may be considered such gender specific risk factors that increase the likelihood of developing FEPM and bipolar disorder. Such information could be used by clinicians working with such "high risk" individuals to identify those who might be at the greatest risk of developing first psychotic manic episode. Future research could also be directed to whether there are gender differences in pharmacological response in patients who are either at high risk or have full threshold disorder.

\section{Endnote}

${ }^{\mathrm{a}}$ For ease of interpretation, female was the reference category for the calculation of this odds ratio.

\section{Abbreviations \\ FEP: First episode psychosis; FEM: First episode mania; FEPM: First episode psychotic mania; FEPOS: First Episode Psychosis Outcome Study; EPPIC: Early Psychosis Prevention and Intervention Centre; DSM-IV: Diagnostic and Statistical Manual of Mental Disorders - fourth edition; ICD-10: International Classification of Disease - $10^{\text {th }}$ edition; CGI-S: Clinical Global Impressions Scale - Severity; CGI- BP: Clinical Global Impressions Scale - Bipolar Disorder; GAF: Global Assessment of Functioning; MVSI: Modified Vocation Status Index; MLCI: Modified Location Code Index; OR: Odds ratio; Cl: Confidence interval.}

\section{Competing interests}

Prof. Lambert, Prof. Conus, Prof. Schimmelmann, and Prof. McGorry have served on the speakers' board of Eli Lily. Prof Berk Berk has served on advisory boards and received funds and/or honoraria from Astra Zeneca, Eli Lilly, Janssen Cilag, Lundbeck, Servier, Glaxo Smith Kline, Organon, Novartis, Pfizer, Bristol Myers Squibb, Sanofi Synthelabo and Solvay.

There are no other relevant disclosures. 


\section{Authors' contributions}

ML, PC, and PM contributed to the design and conduct of FEPOS. SC and MB developed the ideas for this paper. SC wrote the draft of the manuscript and conducted all statistical analyses. ML, PC, PM, FJB, and BGS collaborated in writing and editing of the paper and approved the final manuscript.

\section{Acknowledgements}

The First Episode Outcome Study (FEPOS) was supported by a grant to Prof. Martin Lambert from Eli Lilly Company Australia, and a grant to Prof. Philippe Conus from the Leenaards Foundation, Switzerland. Eli Lilly Australia funded the assessment of files on a subgroup of this cohort treated with olanzapine and risperidone. Associate Prof. Sue Cotton was supported by the Ronald Phillip Griffith Fellowship, Faculty of Medicine, Dentistry, and Health Sciences, The University of Melbourne.

\section{Author details}

'Orygen Youth Health Research Centre, University of Melbourne, Locked Bag 10 (35 Poplar Road), Parkville, Victoria 3052, Australia. ${ }^{2}$ Centre for Youth Mental Health, The University of Melbourne, Parkville, Victoria, Australia. ${ }^{3}$ Psychosis Early Detection and Intervention Centre (PEDIC), Department for Psychiatry and Psychotherapy, Centre for Psychosocial Medicine, University Medical Center Hamburg-Eppendorf, Hamburg, Germany. ${ }^{4}$ School of Medicine, Deakin University, Geelong, Australia. ${ }^{5}$ Florey Institute for Neuroscience and Mental Health, Parkville, Australia. ${ }^{6}$ University Hospital of Child and Adolescent Psychiatry, University of Bern, Bern, Switzerland. ${ }^{7}$ Treatment and Early Intervention in Psychosis Program (TIPP), Département de Psychiatrie CHUV, Université de Lausanne, Clinique de Cery, Prilly, Switzerland

Received: 23 January 2013 Accepted: 28 January 2013 Published: 13 March 2013

\section{References}

1. Cotton SM, Lambert M, Schimmelmann BG, Foley DL, Morley KI, McGorry PD, Conus P: Gender differences in premorbid, entry, treatment and outcome characteristics in a treated epidemiological sample of 661 patients with first-episode psychosis. Schizophr Res 2009, 114:17-24.

2. Hafner H: Gender differences in schizophrenia. Psychoneuroendocrinology 2003, 28(Supp 1):17-54.

3. Hafner H, An-der HW, Behrens S, Gattaz WF, Harnbrecht M, Loffler W, Maurer K, Munk JP, Nowotny B, Reicher RA, et al: Causes and consequences of the gender differences in age of onset of schizophrenia. Schizophr Bull 1998, 24:99-113.

4. Thorup A, Petersen L, Jeppesen P, Ohlenschloeger J, Christensen T, Krarup $G$, Jorgensen P, Nordentoft M: Gender differences in young adults with first-episode schizophrenia spectrum disorders at baseline in the Danish OPUS study. J Nerv Ment Dis 2007, 195:396-405.

5. Diflorio A, Jones I: Is sex important? Gender differences in bipolar disorders. Int Rev Psychiatry 2010, 22:437-452.

6. Grant BF, Stinson FS, Hasin DS, Dawson DA, Chou SP, Ruan WJ, Huang B: Prevalence, correlates, and comorbidity of bipolar I disorder and axis I and II disorders: Results from the National Epidemiologic Survey on Alcohol and related Conditions. J Clin Psychiatry 2005, 66:1205-1215.

7. Kennedy N, Boydell J, Kalidini S, Fearon P, Jones PB, van Os J, Murray RM: Gender differences in incidence and age of onset of mania and bipolar dsiorder over a 35-year period in Camberwell, England. Am J Psychiatry 2005, 162:257-262.

8. Kawa I, Carter JD, Joyce PR, Doughty CJ, Framptom CM, Wells JE, Walsh AES, Olds RJ: Gender differences in bipolar disorder: age of onset, course, comorbidity, and symptom presentation. Bipolar Disord 2005, 7:119-125.

9. Altshuler LL, Kupka RW, Hellemann G, Frye MA, CSugar CA, McElroy SL, Nolen WA, Grunze H, Leverich GS, Keck PE, et al: Gender and depressive symptoms in 711 patients with bipolar disorder evaluated prospectively in the Stanley Foundation Bipolar Treatment Outcome Network. Am J Psychiatry 2010, 167:708-715.

10. Arnold LM: Gender differences in bipolar disorder. Psychiatr Clin North Am 2003, 26:595-620.

11. Liebenluft $\mathrm{E}$ : Issues in the treatment of wormen with bipolar illness. J Clin Psychiatry 1997, 58:5-11.

12. Braunig P, Sharkar R, Effenberger S, Schoofs N, Kruger S: Gender differences in psychotic bipolar mania. Gend Med 2009, 6:326-361.
13. Secunda S, Swann A, Katz M, Koslow SH, Croughan J, Chong SA: Diagnosis and treatment of mixed mania. Am J Psychiatry 1987, 144:96-98.

14. Baldassano CF, Marangell LB, Gyulai L, Ghaemi SN, Joffe H, Kim DR, Sagduyu K, Truman C, Wiesniewski SR, Sachs GS, et al: Gender differences in bipolar dsiorders: retrospective data from the first 500 STEP-BD participants. Bipolar Disord 2005, 7:465-470.

15. Miquel L, Usall J, Reed C, Bertsch JV E, Gonzalez-Pinto A, Angst J, Noeln W, van Rossum I, Haro JM: Gender differences in outcomes of acute mania: a 12 month follow-up study. Arch Women Ment Hith 2011, 14:107-113.

16. Dunayevich E, Keck PE: Prevalence and description of psychotic features in bipolar mania. Curr Psychiatry Rep 2000, 2:286-290.

17. Lish JD, Dime-Meenan S, Whybrow PC, Price RA, Hirschfeld RM: The National Depressive and Manic-depressive Association (DMDA) survey of bipolar members. J Affect Disord 1994, 31:281-294.

18. Lambert M, Conus P, Cotton S, Robinson J, McGorry PD, Schimmelmann BG: Prevalence, predictors, and consequences of long-term refusal of antipsychotic treatment in first episode psychosis. J Clin Psychopharmacol 2010, 30:565-572.

19. Conus P, Lambert M, Cotton S, Bonsack C, McGorry PD, Schimmelmann BG: Rates and predictors of service disengagement in an epidemiological first-episode psychosis cohort. Schizophr Res 2010, 118:256-263.

20. Conus P, Cotton S, Schimmelmann B, McGorry PD, Lambert M: The First-Episode Psychosis Outcome Study: premorbid and baseline characteristics of an epidemiological cohort of 661 first-episode psychosis patients. Early Interv Psychiatry 2007, 1:191-200.

21. Lambert M, Conus P, Lubman DI, Wade D, Yuen H, Moritz S, Naber D, McGorry PD, Schimmelmann BG: The impact of substance use disorders on clinical outcome in 643 patients with first-episode psychosis. Acta Psychiatr Scand 2005, 112:141-148.

22. Robinson J, Cotton S, Conus P, Schimmelmann BG, McGorry PD, Lambert M: Suicide attempt in first-episode psychosis: the demographic, premorbid and clinical predictors of suicide attempt in young people with first-episode psychosis. Aust N Z J Psychiatry 2009, 43:149-157.

23. Schimmelmann BG, Conus P, Edwards J, McGorry P, Lambert M: Diagnostic stability 18-month after a first diagnosis of psychosis. J Clin Psychiatry 2005, 66:1239-1246.

24. Schimmelmann BG, Conus P, Schacht M, McGorry PD, Lambert M: Predictors of service disengagement with treatment in first-admitted adolescents with psychosis. J Am Acad Child Adolesc Psychiatry 2006, 45:990-999.

25. Schimmelmann BG, Conus P, Cotton S, McGorry PD, Lambert M: Pre-treatment, baseline, and outcome differences between early-onset and adult-onset psychosis in an epidemiological cohort of 636 first-episode patients. Schizophr Res 2007, 95:1-8.

26. Schimmelmann BG, Huber CG, Lambert M, Cotton S, McGorry PD, Conus P. Impact of duration of untreated psychosis on pre-treatment, baseline, and outcome characteristics in an epidemiological first-episode psychosis cohort. J Psychiatr Res 2008, 42:982-990.

27. Robinson J, Harris M, Cotton S, Hughes A, Conus P, Lambert M, Schimmelmann BG, McGorry PD: Sudden death among young people with first-episode psychosis: An 8-10 year follow-up study. Psychiatry Res 2010, 177:305-308.

28. McGorry PD, Edwards J, Mihalopoulos C, Harrigan SM, Jackson HJ: EPPIC: an evolving system for early detection and optimal management. Schizophr Bull 1996, 22(2):305-326.

29. Guy W: ECDEC Assessment Manual for Psychopharmacology, Revised. DHEW Pub. No. (ADM) 76-338. Rockville, MD: National Institute of Mental Health; 1976.

30. Tohen M, Hennen J, Zarate CMB RJ, Strakowski SM, Stoll AL, Faedda GL, Suppes T, Gebre-Medhin P, Cohen BM: Two-year syndromal and functional recovery in 219 cases of first episode major affective disorder with psychotic features. Am J Psychiatry 2000, 157:220-228.

31. Fazel S, Lichtenstein P, Grann M, Goodwin GM, Langstrom N: Bipolar and violent crime: new evidence from population based longitudinal studies and systematic review. Arch Gen Psychiatry 2010, 67:931-938.

32. Goldstein Bl, Bukstein OG: Comorbid substance use disorders among youth with bipolar disorder: opportunites for early identification and prevention. J Clin Psychiatry 2010, 71:348-358.

33. Suominen $K$, Mantere $O$, Valtonen $H$, Avrvilommi $P$, Leppamaki S, Isometsa E: Gender differences in bipolar disorder type I and II. Acta Psychiatr Scand 2009, 120:464-473.

34. Goldstein BI, Levitt AJ: The specific burden of comorbid anxiety disorders and substance use in bipolar I disorders. Bipolar Disord 2008, 10:67-78. 
35. Compton WM, Thomas YF, Stinson FS, Grant BF: Prevalence, correlates, disability, and comorbidity of DSM-IV drug abuse and dependence in the United States: results from the national epidemiologic survey on alcohol and related conditions. Arch Gen Psychiatry 2007, 64:566-576.

36. Jaworski F, Dubertret C, Ades J, Gorwood P: Presence of co-morbid substance use in bipolar patients worsens their social functioning to the level observed in patients with schizophrenia. Psychiatry Res 2011, 185:129-134.

37. Dell'Osso B, Buoli M, Bortolussi S, Camuri G, Vecchi V, Altamura AC: Patterns of Axis I comorbidity in relation to age in patients with bipolar disorder: a cross-sectional analysis. J Affect Disord 2011, 130:318-322.

38. Lagerberg TV, Sundet K, Aminoff SR, Berg AO, Ringen PA, Andreassen OA, Melle I: Excessive cannabis use is associated with earlier age at onset in bipolar disorder. Eur Arch Psychiatry Clin Neurosci 2011, 261:397-405.

39. Bertani M, Lasalvia A, Bonetto C, Tosato S, Cristofalo D, Bissoli S, De Santi K, Mazzoncini R, Lazzarotto LS M, Sale A, et al: The influence of gender on clinical and social characteristics of patients at psychosis onset: a report from the Psychosis Incident Cohort Outcome Study (PICOS). Psychol Med 2012, 42:769-780.

40. McCabe KL, Maloney EA, Stain HJ, Loughland CM, Carr VJ: Relationship between childhood adversity and clinical and cognitive features in schizophrenia. J Psychiatr Res 2012, 46:600-607.

41. Archie S, Rush BR, Akhtar-Danesh N, Norman R, Malla A, Roy P, Zipursky RB: Substance use and abuse in first episode psychosis: prevalence before and after early intervention. Schizophr Bull 2007, 33:1354-1363.

42. Macneil CA, Hasty MK, Berk M, Henry L, Evans M, Redlich C, Daglas R, McGorry PD, Conus P: Psychological needs of adolescents in the early phase of bipolar disorder: implications for early intervention. Early Interv Psychiatry 2011, 5:100-107

43. Berk M, Hallam K, Malhi GS, Henry L, Hasty M, Macneil C, Yucel M, Pantelis C, Murphy B, Vieta $E$, et al: Evidence and implications for early intervention in bipolar disorder. J Ment Health 2010, 19:113-126.

44. Pereda N, Guilera G, Forns M, G-B J: The prevalence of child sexual abuse in community and student samples: a meta-analysis. Clin Psychol Rev 2009, 29:328-338.

45. Bebbington PE, Bhugra D, Brugha T, Singleton N, Farrell M, Jenkins R, Lewis G, Meltzer H: Psychosis, victimisation and childhood disadvantage: evidence from the second British National Survey of Psychiatric Morbidity. Br J Psychiatry 2004, 185:220-226.

46. Shevlin M, Dorahy MJ, Adamson G: Trauma and psychosis: an analysis of the National Comorbidity Survey. Am J Psychiatry 2007, 164:166-169.

47. Conus P, Cotton S, Schimmelmann BG, Berk M, Daglas RM PD, Lambert M: Pretreatment and outcome correlates of past sexual and physical trauma in 118 bipolar I disorder patients with a first episode of psychotic mania. Bipolar Disoders 2010, 12:244-252.

48. Conus P, Cotton S, Schimmelmann BG, McGorry PD, Lambert M: Pretreatment and outcome correlates of sexual and physical trauma in an epidemiological cohort of first episode psychosis patients. Schizophr Bull 2010, 36:1105-1114.

49. Fisher H, Morgan C, Dazzan P, Craig TK, Morgan K, Hutchinson G, Jones PB, Doody GA, Pariante C, McGuffin P, et al: Gender differences in the association between childhood abuse and psychosis. Br J Psychiatry 2009, 194:319-325.

50. Meade CS, McDonald LJ, Graff FS, Fitzmaurice GM, Griffin ML, Weiss RD: A prospective study examining the effects of gender and sexual/physical abuse on mood outcomes in patients with co-occuring bipolar I and substance use disorders. Bipolar Disord 2009, 11:425-433.

51. Romero S, Birmaher B, Axelson D, Goldstein T, Goldstein Bl, Gill MK, losif A, Strober MA, Hunt J, Esposito-Smythers C, et al: Prevalence and correlates of physical and sexual abuse in children and adolescents with bipolar disorder. J Affect Disord 2009, 112:144-150.

52. Davidson G, Shannon C, Mulholland CC, Campbell J: A longitudinal study of the effects of childhood trauma on symptoms and functioning of people with severe mental health problems. J Trauma Dissociation 2009, 10:57-68.

53. Early Psychosis Prevention and Intervention Centre (EPPIC): Australian Clinical Guidelines for Early Psychosis. Secondth edition. Melbourne: University of Melbourne; 2010.

54. Bechdolf A, Nelson B, Cotton SM, Chanen A, Thompson AD, Kettle JC $P$, Amminger GP, Yung AR, Berk M, McGorry PD: A preliminary evaluation of the validity of at risk criteria for bipolar disorders in help-seeking adolescents and young adults. J Affect Disord 2010, 127:316-320.
55. Conus P, Ward J, Lucas N, Cotton S, Yung AR, Berk M, McGorry PD: Characterisation of the prodrome to a first episode of psychotic mania: results of a retrospective study. J Affect Disord 2010, 124:341-345.

56. Berk M, Conus P, Lucas N, Hallam K, Malhi GS, Dodd S, Yatham LN, Yung A, McGorry PD: Setting the stage: from prodrome to treatment resistance in bipolar disorder. Bipolar Disord 2007, 9:671-678.

doi:10.1186/1471-244X-13-82

Cite this article as: Cotton et al:: Gender differences in first episode psychotic mania. BMC Psychiatry 2013 13:82.

\section{Submit your next manuscript to BioMed Central and take full advantage of:}

- Convenient online submission

- Thorough peer review

- No space constraints or color figure charges

- Immediate publication on acceptance

- Inclusion in PubMed, CAS, Scopus and Google Scholar

- Research which is freely available for redistribution

Submit your manuscript at www.biomedcentral.com/submit
C BioMed Central 